\title{
GAS CHROMATOGRAPHY MASS SPECTROSCOPY ANALYSIS AND PREDICTION OF BIOACTIVITIES IN THE CHLOROFORM EXTRACT OF HALYMENIA DILATATA ZANARDINI (RED ALGAE) COLLECTED FROM MANDAPAM, TAMIL NADU, INDIA
}

\author{
FREDRICK RAJA E, JOHN PETER PAUL J* \\ Department of Botany, St. Xavier's College (Autonomous), Affiliated to Manonmaniam Sundaranar University, Tirunelveli, Tamil Nadu, \\ India. Email: johnarock2008@yahoo.com
}

Received: 15 August 2021, Revised and Accepted: 14 October 2021

ABSTRACT

Objective: This study was to determine the presence of biochemicals and prediction of bioactivities in the chloroform extract of Halymenia dilatata Zanardini (Red algae) collected from Mandapam, Tamil Nadu, India.

Methods: The active biological components in the chloroform extract of $H$. dilatata Zanardini were studied using gas chromatography mass spectroscopy (GC-MS), and the biological activities were predicted by prediction activity spectra for substances technique.

Results: The analysis revealed the two bioactive components such as N-Hexadecanoic acid (5.384\%) and 1,2-Benzenedicarboxylic acid, Mono(2Ethylhexyl) Ester (94.616\%). In 1,2-Benzenedicarboxylic acid, Mono(2-Ethylhexyl) Ester, 1933 biological activities were predicted. Among the biological activities, 74 were highly active and their Pa score is above 70\%. In Pa>0.7, there a 15 different activities are predicated including antitumor (91.5\%) followed by anti-inflammatory (89.7\%), antimicrobial (84.7\%), anti-inflammatory (74.5\%), etc.

Conclusion: The present study provided the bioactive components present in the chloroform extract of $H$. dilatata Zanardini by GC-MS analysis and the prediction of biological studies by prediction of activity spectra for substances.

Keywords: Gas chromatography mass spectroscopy, Prediction of activity spectra for substances, Halymenia dilatata, Antieczematic.

(C) 2021 The Authors. Published by Innovare Academic Sciences Pvt Ltd. This is an open access article under the CC BY license (http://creativecommons.org/ licenses/by/4.0/) DOI: http://dx.doi.org/10.22159/ajpcr.2021v14i12.43068. Journal homepage: https://innovareacademics.in/journals/index.php/ajpcr

\section{INTRODUCTION}

The marine ecosystem is the largest of earth's aquatic ecosystems and is distinguished by waters that have a high salt content. For $80 \%$ of the world's animal and plant species mostly depend on the marine ecosystem [1]. Nowadays, attention is on finding drugs from natural sources rather than the synthetic produced chemicals [2]. Marine algae becomes a most valuable and viable exposed material because the algal species posses different minerals, iodine, proteins, vitamins, fats, bromine, bioactive substances making them as a good source of good and medicine [3]. Marine algae are one of the valuable natural resources for producing varieties of bioactive secondary metabolites that have the potential to be used in the development of new pharmaceutical and industrial agents [4]. Algae have long been used in traditional medicine and also some algae have bactericidal, antifungal, antiviral, and antitumor activity; they have been extensively studied by several researchers [5].

Macro-algae are classified into three taxonomic groups depend on the pigmentation, green algae, red algae, and brown algae [6]. Red algae have developed long- and short-term habitual strategies for survival under a variety of seasonal variation, involving changes in the thallus morphology, differences in chloroplast morphology and photosynthetic membrane composition and functionality at the molecular level (shortterm habitual strategies). The red algal genus Halymenia includes 63 accepted species and infraspecific names among these most of the species are reported from cold temperature but the highest diversity from the warm climate and tropical regions $[7,8]$. The organic substances could be attained in both primary and secondary metabolic process; they also provide a source of medicine since the earliest time. Marine algae are one of the prevalent and auspicious sources of various bioactive secondary metabolites. Their revelation has intensified in the past few decades [9]. Numerous halogenated compounds have already been broadcast from red algal species [10]. Halymenia dilatata revealed some of the chemically active compounds that help for medicinal purposes and benefit the fishes in their growth and survival [11]. Therefore, the bioinformatics tool prediction of activity spectra for substances (PASS), one of the premising ways to predict the biological activity, has been selected to predict the bioactivities. PASS predictions are based on a structure activity relationship (SAR). More than 64 million PASS predictions for nearly 250,000 compounds were available on the web from open NCI database including more than 4700 biologically active compounds [11]. The purpose of this study is to determine the phytochemicals present in the chloroform extract of $H$. dilatata Zanardini with the aid of gas chromatography mass spectroscopy (GC-MS) technique to predict the biological activity of the chemical compounds.

\section{METHODS}

Collection of sample

The red algal species, $H$. dilatata Zanardini were collected from Mandapam coastal line (Lat. $9^{\circ} 16^{\prime} 48.00^{\prime \prime} \mathrm{N}$ Longitude: $79^{\circ} 07^{\prime} 12.00^{\prime \prime}$ E), Ramanathapuram district in the south east coast of Tamil Nadu, India. The collected algal species was authenticated and deposited in Xavier's College Herbarium, Centre for Biodiversity and Biotechnology, St. Xavier's College (Autonomous), Palayamkottai-627002, and the Voucher number (XCH20506) was also given for the red algal species. Samples were collected by hand picking during low wave and flushed with marine water to remove debris and epiphytes. The entire epiphytes were expelled using soft brush. In the laboratory, the samples are once again washed in freshwater and stored in refrigerator for further analysis [12].

Preparation of extract

The plant specimens were washed with distilled water and placed on blotting paper and spread out at room temperature in the shade 
condition for drying. The shade dried samples were grounded to fine powder using a tissue blender. The fine powdered samples were then stored in the refrigerator for further analysis. $30 \mathrm{~g}$ of the fine powdered samples were packed in the Soxhlet apparatus and extracted with chloroform for $8 \mathrm{~h}$ separately [13].

\section{GC-MS analysis}

GC-MS analysis was performed on a Perkin Elmer Turbo Mass Spectrophotometer (Norwalk, CT06859, and USA) using a Perkin Elmer Auto sampler XLGC. The column used was Perkin Elmer Elite - 5 capillary column measuring $30 \mathrm{~m} \times 0.25 \mathrm{~mm}$ with a film thickness of $0.25 \mathrm{~mm}$ composed of $95 \%$ Dimethyl polysiloxane. Helium was used as a carrier gas at a flow rate of $1.0 \mathrm{ml} / \mathrm{min} .1 \mu \mathrm{l}$ sample injection volume was utilized. The equipment was fixed to an initial temperature of $60^{\circ} \mathrm{C}$ and continuously maintained at this temperature for $2 \mathrm{~min}$, and at the final time period the oven temperature was raised up to $300^{\circ} \mathrm{C}$, at the rate of an increase of $10^{\circ} \mathrm{C} / \mathrm{min}$ and maintained for $6 \mathrm{~min}$. Injection port was maintained as $250^{\circ} \mathrm{C}$ in temperature. Total run time was $90 \mathrm{~min}$. Mass spectra was evaluated using electron impact ionization at $70 \mathrm{eV}$ with ion source temperature of $240^{\circ} \mathrm{C}$, and the interface temperature was maintained at $240^{\circ} \mathrm{C}$ and the data were analyzed using total ion count to identify the compound and quantification. The scanning range was 50-600 mass units. The chemical constituents were identified by GC-MS.

Interpretation of mass spectrum of GC-MS was conducted using the database of the National Institute Standard and Technology (NIST) having more than 62,000 patterns. The spectrum of the components was compared to the database of the spectrum of the known components stored in the NIST library. Measurement and data processing of peak areas were carried out by Turbo-Mass OCPTVS-Demo SPL software. The Biological activities of the particular compound are exploited by using online PASS software [14].

\section{Biological activity}

Prediction of the biological activity based on structural formula of a chemical compound to reveal novel biological activities of selected compounds, its mechanism and related side effects using software. The biological activity spectra of those phytoconstituents were evaluated by PASS version (version 9.1, http://195.178.207.233/PASS). PASS software product attains more than 64 million predictions of over 500 different biological activities. Several research reports are available about this approach to predicting the various functional of natural products [15]. Biological activities based on structural formula of a chemical compound predict the (i) Pa (probability "to be active") evaluates the possibility that the predicted compound belongs to the category of active compounds. (ii) Pi (probability "to be inactive") evaluates the possibility that the predicted compound belongs to the category of inactive compounds [16]. Being probabilities, the Pa and Pi esteems fluctuate from 0.000 to 1.000 and its addition is not equal to zero that is $\mathrm{Pa}+\mathrm{Pi} \neq 1$, since these probabilities are determined independently. The PASS prediction were deciphered and utilized in an adaptable way. (i) only activities with $\mathrm{Pa}>\mathrm{Pi}$ are considered as workable for a specific compound; (ii) if $\mathrm{Pa}>0.7$, the opportunity to find the activity experimentally is high; (iii) if $0.5<\mathrm{Pa}<0.7$, the chance to discover the action tentatively is less, however the compound is probably not so similar to known drug specialists; (iv) if $\mathrm{Pa}<0.5$, the chance to find the activity experimentally is less, yet the chance to find a structurally new compound, that is, new chemical entries is more [17].

\section{RESULTS AND DISCUSSION}

\section{GC-MS analysis}

GC-MS analysis of $H$. dilatata Zanardini shows the two major peaks which show the presence two compounds in chloroform extract (Fig. 1). The expecting compounds in chloroform extracts were $\mathrm{N}$-Hexadecanoic acid (5.384\%) and 1,2-Benzenedicarboxylic acid, Mono(2-Ethylhexyl) Ester $(94.616 \%)$. The spectrum profile of GC-MS confirmed the presence of two components with retention time (RT) 20.565 and 22.326. The identified compounds with their RT, molecular formula, molecular weight (MW), percentage composition, and structure are presented in Table 1.

The chemical nature of the identified compounds were found to be from the Palmitic acid, Phthalic acid ester and reported to possess antimicrobial, antioxidant, nematicide, pesticide, antiandrogenic, and antifouling (Table 2). The antifouling, antibacterial and antifungal property of palmitic acid were also identified and reported [18,19]. The antitumor, anti-inflammatory, antimicrobial properties, antileukemic, and antimutagenic properties of phthalic acid were also identified and reported $[20,21]$.

\section{Prediction of biological activity spectra and effects}

The identifying compounds in chloroform extracts from GC-MS analysis were $\mathrm{N}$-Hexadecanoic acid (5.384\%) and 1,2-Benzenedicarboxylic acid, Mono(2-Ethylhexyl) Ester (94.616\%). 1,2-Benzenedicarboxylic acid, Mono(2-Ethylhexyl) Ester occupies 94.616 percentage of area, were analyzed for biological activity by PASS software. In Pa $>0.7$, there a 74 different activities are predicated (Table 3). All the 74 activities are fall in the four categories are mechanism of action, metabolic terms, pharmacotherapeutic effects, and adverse and toxic effects. There are 62 different types of mechanism of action including sugar-phosphatase inhibitor, lipid metabolism regulator, nitrate reductase (cytochrome) inhibitor, and urethanase inhibitor. Two types of metabolic terms including CYP2J substrate and CYP2J2 substrate, two types of Adverse and toxic effects including eye irritation and skin irritation and 8 types of pharmacotherapeutic effects including cholesterol antagonist, phobic disorders treatment, antiseborrheic, fibrinolytic, antieczematic, sclerosant antihypercholesterolemic, and macrophage colony stimulating factor agonist (Table 4).

\section{DISCUSSION}

Two different compounds namely hexadecanoic acid (5.384\%) and 1,2-benzenedicarboxylic acid, mono(2-ethylhexyl) Ester (94.616\%) were isolated using GC-MS analysis. 1,2-Benzenedicarboxylic acid, Mono(2-Ethylhexyl) Ester occupies $94.616 \%$ of area, reveals 74

Table 1: Active compounds identified in the chloroform extract of $\boldsymbol{H}$. dilatata Zanardini

\begin{tabular}{lllll}
\hline Name of the compound & RT & PA \% & MW & MF \\
\hline N-Hexadecanoic acid & 20.565 & 5.384 & 256 & C16 \\
1,2-Benzenedicarboxylic acid, Mono (2-Ethylhexyl) Ester & 22.326 & 94.616 & \\
\hline
\end{tabular}

RT: Retention time, PA\%: Peak area\%, MW: Molecular weight, MF: Molecular formula, H. dilatata: Halymenia dilatata 


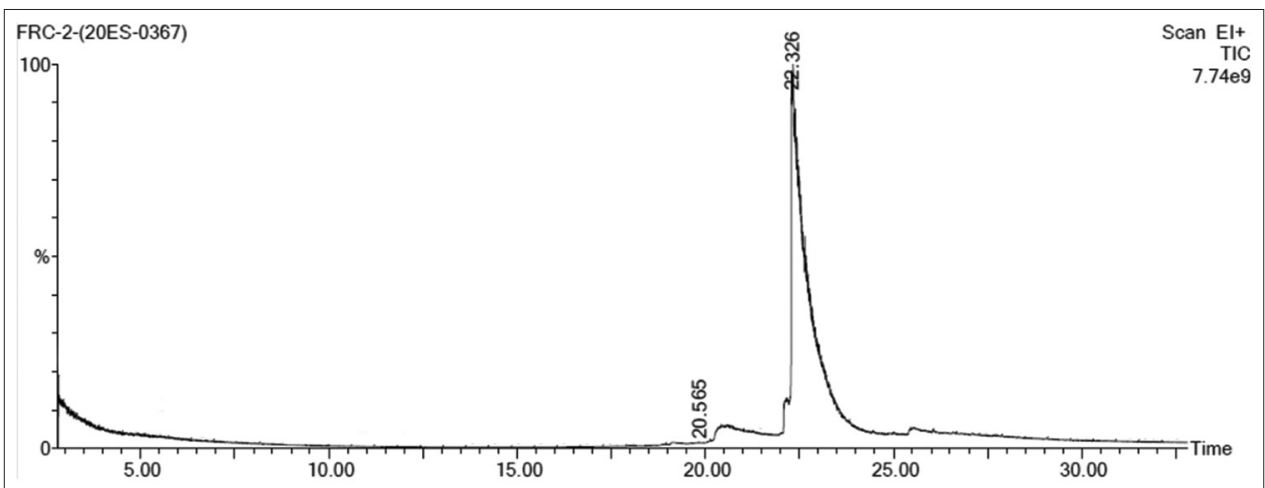

Fig. 1: Gas chromatography mass spectroscopy chromatogram of the chloroform extract of Halymenia dilatata Zanardini

Table 2: Chemical nature and biological activity of phyto-components identified in the chloroform extract of H. dilatata Zanardini

\begin{tabular}{|c|c|c|}
\hline Name of the compound & $\begin{array}{l}\text { Chemical } \\
\text { nature }\end{array}$ & Biological activity \\
\hline N-Hexadecanoic acid & $\begin{array}{l}\text { Palmitic } \\
\text { acid }\end{array}$ & $\begin{array}{l}\text { Antifouling, antibacterial } \\
\text { and antifungal }\end{array}$ \\
\hline $\begin{array}{l}\text { 1,2-Benzenedicarboxylic } \\
\text { acid, Mono (2-Ethylhexyl) } \\
\text { Ester }\end{array}$ & $\begin{array}{l}\text { Phthalic } \\
\text { acid ester }\end{array}$ & $\begin{array}{l}\text { Antitumor, anti-inflammatory, } \\
\text { antimicrobial properties, } \\
\text { antileukemic and } \\
\text { antimutagenic }\end{array}$ \\
\hline
\end{tabular}

Table 3: The number of biological activities of 1,2-benzenedicarboxylic acid, mono (2-ethylhexyl) Ester predicted by the PASS in the chloroform extract of $H$. dilatata Zanardini

\begin{tabular}{|c|c|c|}
\hline $\begin{array}{l}\text { Biological spectra } \\
\text { (categories) }\end{array}$ & $\begin{array}{l}\text { Number of } \\
\text { activities }\end{array}$ & Examples \\
\hline Mechanism of Action & 62 & $\begin{array}{l}\text { Sugar-phosphatase } \\
\text { inhibitor, Lipid metabolism } \\
\text { regulator, Nitrate reductase } \\
\text { (cytochrome) inhibitor, } \\
\text { Urethanase inhibitor etc }\end{array}$ \\
\hline Metabolic terms & 2 & $\begin{array}{l}\text { CYP2J substrate and CYP2J2 } \\
\text { substrate }\end{array}$ \\
\hline $\begin{array}{l}\text { Pharmacotherapeutic } \\
\text { effects }\end{array}$ & 8 & $\begin{array}{l}\text { Antitumor, } \\
\text { anti-inflammatory, } \\
\text { antimicrobial, antileukemic } \\
\text { and antimutagenic, } \\
\text { Cholesterol antagonist, } \\
\text { phobic disorders treatment, } \\
\text { antihypercholesterolemic, } \\
\text { macrophage colony } \\
\text { stimulating factor agonist }\end{array}$ \\
\hline Adverse and toxic effects & 2 & $\begin{array}{l}\text { Eye irritation and Skin } \\
\text { irritation }\end{array}$ \\
\hline
\end{tabular}

PASS: Prediction of activity spectra for substances, H. dilatata: Halymenia dilatata

activities using PASS software. All the 74 activities are fall in the four categories including pharmacotherapeutic effects. Antitumor activity is one of the pharmacotherapeutic effects can predicted from the targetable compound. Hexadecanoic acid is a saturated fatty acid found in the human body and can be provided in the diet or synthesized endogenously from other fatty acids, carbohydrates and amino acids. It represents $20-30 \%$ of total fatty acids in membrane phospholipids and adipose triacylglycerols. On average, a $70 \mathrm{~kg}$ man is made up of $3.5 \mathrm{~kg}$
Table 4: Prediction activity spectra for 1,2-benzenedicarboxylic acid, mono (2-ethylhexyl) ester by PASS system

\begin{tabular}{|c|c|c|c|}
\hline Structure & $\begin{array}{l}\text { Active, } \\
\text { Pa }\end{array}$ & $\begin{array}{l}\text { Inactive } \\
P_{i}\end{array}$ & Activity Spectra \\
\hline \multirow{16}{*}{$\begin{array}{l}\text { 1,2-Benzenedicarboxylic } \\
\text { acid, Mono } \\
\text { (2-Ethylhexyl) Ester }\end{array}$} & 0.915 & 0.005 & \multirow{3}{*}{$\begin{array}{l}\text { Antitumor, } \\
\text { Antineoplastic } \\
\text { anti-inflammatory, } \\
\text { Antieczematic }\end{array}$} \\
\hline & & & \\
\hline & 0.897 & 0.005 & \\
\hline & 0.847 & 0.005 & Antimicrobial, \\
\hline & & & Apoptosis agonist \\
\hline & 0.792 & 0.003 & $\begin{array}{l}\text { Transcription factor } \\
\text { stimulant }\end{array}$ \\
\hline & 0.792 & 0.003 & antileukemic \\
\hline & 0.799 & 0.021 & antimutagenic \\
\hline & 0.763 & 0.005 & Antineoplastic (lung \\
\hline & 0.760 & 0.004 & $\begin{array}{l}\text { MMP9 expression } \\
\text { inhibitor }\end{array}$ \\
\hline & 0.745 & 0.011 & Anti-inflammatory \\
\hline & 0.734 & 0.005 & Antipsoriatic \\
\hline & 0.734 & 0.006 & Dermatologic \\
\hline & 0.722 & 0.002 & $\begin{array}{l}\text { NF-E2-related factor } 2 \\
\text { stimulant }\end{array}$ \\
\hline & 0.709 & 0.011 & Phosphatase inhibitor \\
\hline & 0.746 & 0.048 & CYP2C12 substrate \\
\hline
\end{tabular}

of Hexadecanoic acid. The tight homeostatic control of hexadecanoic acid tissue concentration is likely related to its fundamental physiological role in several biological functions. Particularly in infants, hexadecanoic acid seems to play a crucial role as recently thoroughly revised by Innis [22]. The disruption of hexadecanoic acid homeostatic balance, implicated in different physiopathological conditions such as atherosclerosis, neurodegenerative diseases and cancer, is often related to an uncontrolled hexadecanoic acid endogenous biosynthesis, irrespective of its dietary contribution. 1,2-benzenedicarboxylic acid, mono(2-ethylhexyl) Ester can be used as a precursor to synthesize dioctyl phthalate, a widely used plasticizer, via esterification reaction with 2-ethylhexanol. Both animal and human epidemiologic data support the hypothesis that phthalates lead to reductions in thyroid hormone levels [23]. Several studies have also shown a positive association between urinary phthalates and serum thyroid-stimulating hormone, although the overall strength of this association is weaker than that between urinary phthalates and serum thyroid hormone levels. As with resorcinol, phthalates are among the many chemicals found to be present at higher levels in drinking water consumed in areas with higher goiter prevalence [24].

In $\mathrm{Pa}>0.7$, there a 15 different activities are predicated including antitumor $(91.5 \%)$ followed by anti-inflammatory (89.7\%), antimicrobial $(84.7 \%)$, anti-inflammatory $(74.5 \%)$, etc. Prediction of biological activity with the PASS software, keeping the compound 
identified from the GC-MS analysis. The structure and specific activity of the compound also can be predicted. In the PASS software system, the prediction of the biological spectra of the new compounds is based on the SAR (based on SAR) and the training set contains 117332 known biological active substances (drugs, pharmacological probes, leads and toxic compounds). The activity spectrum is arranged in descending order. In the spectrum of biological activity, the most probable is ranked at the first and the less probable is ranked at the lowest. The $\mathrm{Pa}$ and $\mathrm{Pi}$ esteems fluctuate from 0.000 to 1.000 . For biological review, $\mathrm{Pa}>0.7$ to find the activity experimentally is high. Even though there is a computational method, based on the two dimensional structure of the molecule PASS is not being able to give an accurate prediction and does not calculate the molecular energy levels. For further confirmation of the activity, it is necessary to confirm with further in vitro and in vivo studies.

\section{CONCLUSION}

In the present study, the active biological components in the chloroform extract of $H$. dilatata Zanardini were studied using GC-MS analysis and the biological activities were predicted by PASS technique. The analysis revealed two bioactive components such as $\mathrm{N}$-Hexadecanoic acid (5.384\%) and 1,2-Benzenedicarboxylic acid, Mono(2-Ethylhexyl) Ester (94.616\%). In 1,2-Benzenedicarboxylic acid, Mono(2-Ethylhexyl) Ester, 1933 biological activities were predicted. Among the biological activities, 74 were highly active and their Pa score is above $70 \%$. In $\mathrm{Pa}>0.7$, there a 15 different activities are predicated including antitumor (91.5\%) followed by anti-inflammatory $(89.7 \%)$, antimicrobial $(84.7 \%)$, antiinflammatory $(74.5 \%)$, etc. The present study has been provided the bioactive components present in the chloroform extract of $H$. dilatata Zanardini by GC-MS analysis and the prediction of biological studies by PASS. Future strategies are required to validate these predictions.

\section{ACKNOWLEDGMENTS}

The first author is thankful to Dr. J. John Peter Paul, Assistant Professor in Botany and Director, Centre for Advanced Research in Plant Sciences, St. Xavier's College (Autonomous), Palayamkottai-627002, Tamil Nadu, India, for his valuable guidance for the publication.

\section{AUTHORS' CONTRIBUTIONS}

All authors have contributed equally.

\section{CONFLICTS OF INTERESTS}

Authors declare no conflicts of interests.

\section{FUNDING}

Nil.

\section{REFERENCES}

1. Bhatnagar I, Kim SK. Immense essence of excellence: marine microbial bioactive compounds. Mar Drugs 2010;8:2673-701.

2. Blunt JW, Copp BR, Keyzers RA, Munro MH, Prinsep MR. Marine natural products. Nat Prod Rep 2017:34:235-94.

3. Kandale A, Meena AK, Rao MM, Panda P, Mangal AK, Reddy G, et al. Marine algae: An introduction, food value and medicinal uses. J Pharm Res 2011;4:219-22.
4. Rico M, Gonzalez AG, Casiano MS, Gonzalez-Davila M, Almeida NP, De Tangil MS. Production of primary and secondary metabolites using algae. In: Prospects and Challenges in Algal Biotechnology. Springer: Singapore; 2017. p. 311-26.

5. Justo GZ, Silva MR, Queiroz ML. Effects of green algae Chlorella vulgaris on the response of the host hematopoietic system to intraperitoneal Ehrlich ascites tumour transplantation in mice. Immunopharm Immunotoxicol 2001;23:109-31.

6. Pereira L. Littoral of Viana do Castelo-ALGAE: Uses in Agriculture, Gastronomy and Food Industry (Bilingual). Viana Do Castelo: Camara Municipal de Viana Do Castelo; 2010. p. 68.

7. Monroe K, Poore AG. Light quantity and quality induce shade-avoiding plasticity in a marine macroalga. J Evol Biol 2005;18:426-35.

8. Guiry MD, Guiry GM. Algae Base. World-wide Electronic Publication. Ireland: National University of Ireland; 2011.

9. Da Gama BA, Pereira RC, Carvalho AG, Coutinho R, YoneshigueValentin Y. The effects of seaweed secondary metabolites on biofouling. Biofouling 2002;18:13-20.

10. Kamada T, Vairappan CS. New bioactive secondary metabolites from Bornean red alga, Laurencia similis (Ceramiales). Nat Prod Commun 2013;8:287-8

11. Jainab BS, Azeez A, Fathima A, Kumar R. GC-MS analysis of the marine algae Halymenia dilatata Zanardini a potential source of fish feed in future. Indian Hydrobiol 2019;18:164-9.

12. Paul JJ. Phytochemical studies on Turbinaria ornata (Turner) J. Ag. Am J PharmTech Res 2012;2:1-8.

13. Guldhe A, Singh B, Ansari FA, Sharma Y, Bux F. Extraction and conversion of microalgal lipids. In: Algae Biotechnology. Switzerland: Springer International Publishing; 2016.

14. Filimonov DA, Lagunin AA, Gloriozova TA, Rudik AV, Druzhilovskii DS, Pogodin PV, et al. Prediction of the biological activity spectra of organic compounds using the PASS online web resource. Chem Heterocycl Comp 2014;50:444-57.

15. Basha SA, Yunoos M, Ahmed J. PASS: A computerized prediction of biological activity spectra for chemical substances. Indo Am J Pharm 2018;8:6.

16. Zotchev SB, Stepanchikova AV, Sergeyko AP, Sobolev BN, Filimonov DA, Poroikov VV. Rational design of macrolides by virtual screening of combinatorial libraries generated through in silico manipulation of polyketide synthases. J Med Chem 2006;49:2077-87.

17. Marwaha A, Goel RK, Mahajan MP. PASS-predicted design, synthesis and biological evaluation of cyclic nitrones as nootropics. Bioorg Med Chem Lett 2007; 17:5251-5.

18. Bazes A, Silkina A, Douzenel P, Fay F, Kervarec N, Morin D, et al. Investigation of the antifouling constituents from the brown alga Sargassum muticum (Yendo) Fensholt. J Appl Phycol 2009;21:395-403.

19. Agoramoorthy G, Chandrasekaran M, Venkatesalu V, Hsu MJ. Antibacterial and Antifungal activities of fatty acid methyl esters of the blind-your-eye mangrove from India. Braz J Microbiol 2007;38:739-42.

20. Shengbo G, Wanxi P, Dongli L, Bo M, Minglong Z, Daochun Q. Study on antibacterial molecular drugs in Eucalyptus granlla wood extractives by GC-MS. Pak J Pharm Sci 2015;28:1445-8.

21. Lee KH, Kim JH, Lim DS, Kim CH. Anti-leukemic and anti-mutagenic effects of di-(2-ethylhexyl) phthalate isolated from Aloe vera Linn. J Pharm Pharmacol 2000;52:593-8

22. Innis SM. Palmitic acid in early human development. Crit Rev Food Sci Nutr 2016;56:1952-9.

23. Eisenbrand G, Gelbke H. Erratum to: Assessing the potential impact on the thyroid axis of environmentally relevant food constituents/ contaminants in humans. Arch Toxicol 2016;90:1859.

24. Nancy L, Dahlia M, David R. Atomic Data Access in Distributed Hash Tables. International Workshop on Peer-to-Peer Systems. Berlin, Heidelberg: Springer; 2002. p. 295-305. 